direction, the work of the Wills Laboratory has shown a certain apparent diversity with an under. lying unity; instead of a team working in one subject, he has collected around him a group of individuals, each following his bent and working on his own problems, and yet, through the constant discussions and the friendly spirit that he has created, helping and stimulating each other all the time. Nothing is more important, and nothing expresses more clearly the character and worth of the direction of a laboratory, than the general tone of the relations of the people in it, and no better tribute to Prof. Tyndall can be given than the fact that all those who have left his Laboratory have done so reluctantly. His relations with the undergraduate population of the University have displayed the same individual interest, and graduates who have qualified in his Laboratory remember him as a friend as well as a very gifted teacher. He will carry with him into his retirement a warmth of affection and an admiration that can rarely have been equalled, and with them a consciousness of the great part he has played in the development of the University of which he is so distinguished a graduate.

\section{Prof. W. C. McC. Lewis, F.R.S.}

THE retirement of Prof. W. C. McC. Lewis from the Grant-Brunner chair of inorganic and physical chemistry in the University of Liverpool marks the end of an epoch in the development of physical chemistry in Great Britain. His early work with Prof. F. G. Donnan on the experimental examination of the Gibbs adsorption equation is not c nly a classic in the field of colloid science, but also gave him, and afterwards his many junior workers, an interest in the physico-chemical and quantitative aspects of colloids. When the discovery of unimolecular reactions, especially in nitrogen pentoxide, raised the problem of the mechanism of molecular activation in an acute form, Lewis was one of the first with Trautz and Perrin to develop the radiation hypothesis of chemical activation. A series of most interesting and stimulating papers in this field shows the breadth and comprehensiveness of these investigaticns. While the radiation hypothesis is no longer tenable, the significance of the various 'quantum' relationships which obtain in many well-known physico-chemical relationships, for example, Trouton's rule, are still important and await a fuller treatment. Prof. Lewis's threevolume text-book on physical chemistry is one of the standard texts on the subject. The advantages for the readers of a comprehensive text-book written by one author are so evident that their thanks must surely be a recompense to anyone who undertakes such a monumental work.

\section{Sugar Research Foundation Prize: Dr. Leslie F. Wiggins}

Dr. Leslie F. Wiggins, of the Department of Chemistry, University of Birmingham, has been awarded the third annual Sugar Research Foundation Prize of 5,000 dollars, administered by the National Science Fund on behalf of the Sugar Research Foundation, Inc. Dr. Robert C. Hockett, scientific director of the Foundation, described the work of Dr. Wiggins as "a milestone in the advance toward better use of cheap and abundant plant products to serve the myriad needs of civilization. With the depletion of coal and petroleum reserves, greater dependence must be put on utilizing the continuing supply of material produced by growing plants".
He stressed the international character of the plan for studies of sugar as a food and an industrial material. Some phases have been undertaken in Britain through the Colonial Products Research Council and the Imperial College of Tropical Agriculture in Trinidad. Early this year Dr. Wiggins accepted an appointment as director of research in sugar technology at the latter College, and will continue to work at Birmingham until his institute in Trinidad has been built. $\mathrm{He}_{\mathrm{e}}$ will also interest himself closely with projects of the Sugar Research Foundation in the United States and Canada.

Dr. Wiggins has made notable progress in using sugar as a raw material for chemical industry. The principal pathway is through the intermediate, lævulinic acid. Dr. Wiggins has worked out an efficient conversion method and gone on to make such varied products as sulpha drugs, analgesics, and nylon ingredients from the acid. The Birmingham School has also shown that the sodium salt of lævulinic acid makes a good anti-freeze, which can probably be made more cheaply than glycol or glycerine. Several drugs useful for reducing blood pressure, solvents, emulsifying and wetting agents, and a wholly chemical method for producing lactic acid have been developed. Through these channels it is expected that sugar will enter a wide range of uses, from plexiglass-type plastics to solutions for treating hides. In winning the third intermediate prize of 5,000 dollars, Dr. Wiggins becomes eligible for the grand award of 25,000 dollars to be given by the National Science Fund in 1950. The first Sugar Research Foundation prize was shared by Drs. W. Z. Hassid, H. A. Barker and Michael Duodoroff, for the first synthesis of sugar which has made possible 'tracer' studies of the metabolism of sugar in the human body. Dr. Carl F. Cori received the second annual award in 1947 for his contributions to the knowledge of how the body uses starches and sugars.

\section{Mathematics at Birkbeck College, London :}

Dr. P. Dienes

Prof. Paul Dienes, who is retiring from the chair of mathematics at Birkbeck College, London, came to Great Britain from Hungary via Paris twentyseven years ago, after the upheavals of the First World War, as a representative of the Paris school of mathematics. His first line of research was ecm. plex function theory where, among other results, he established the outstanding fact that in many cases the type of divergence of the Taylor series reveals the type of singular behaviour of the function represented by that Taylor series. His results on this problem are collected in his monograph "Sur les singularités des fonctions analytiques" in Borel's collection. At the late Prof. G. H. Hardy's invitation he also wrote a substantial treatise, "The Taylor Series", on complex function theory (Oxford University Press). His second line of research was the differential geometry of curved spaces in connexion with relativity theory. His publications on this subject appeared in English, French and Italian periodicals. Prof. Dienes also obtained new results on infinite matrices and recently about Stieltjes integration. Besides these contributions to the main body of mathematics, he maintained a lively interest in logical and structural problems in connexion with the antinomies. His attitude towards philosophical problems in mathematics could be described as constructive-realist of the Borel-Brouwer type, rather than Russell's logicist-nominalist type. 